
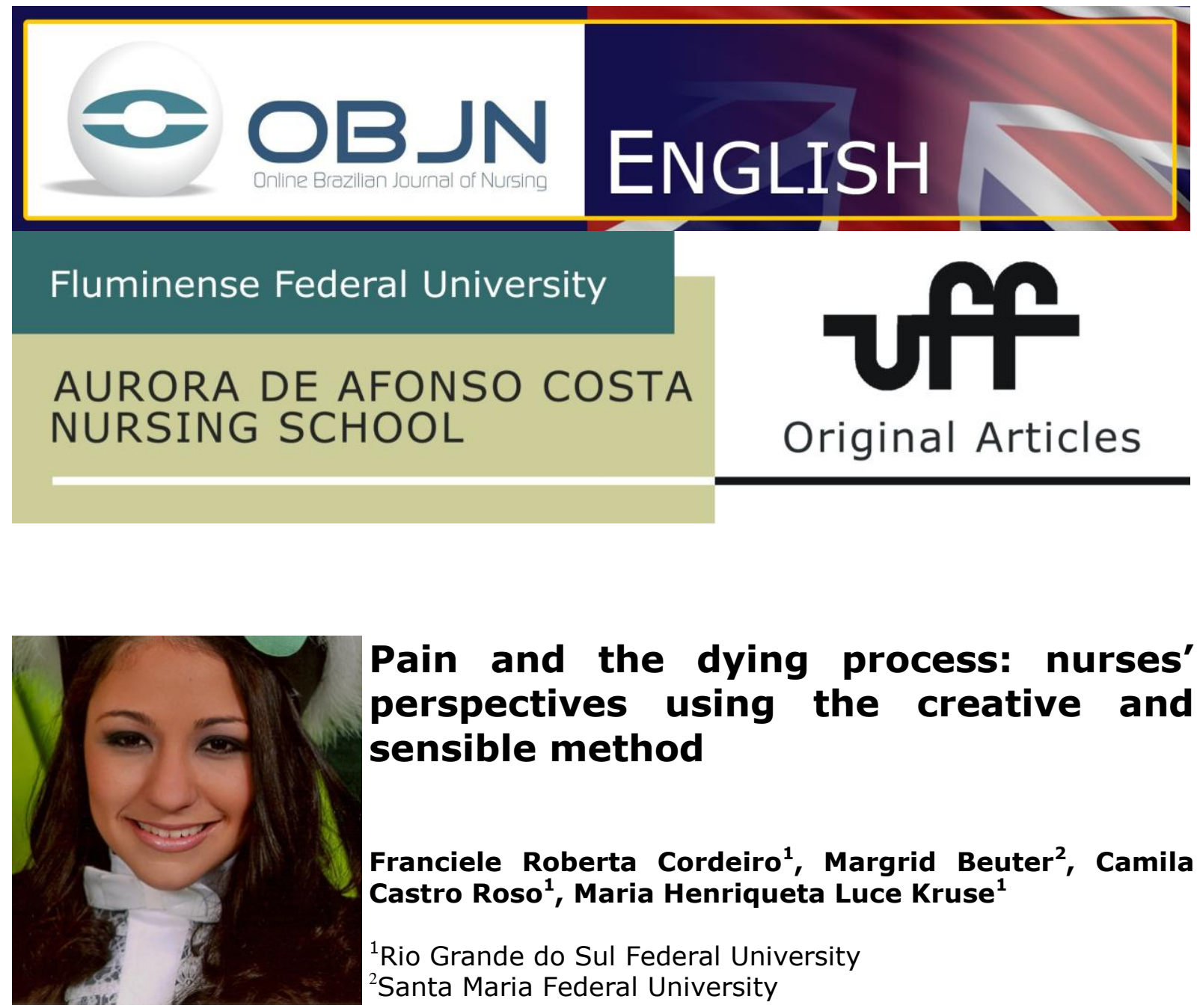

\title{
Pain and the dying process: nurses' perspectives using the creative and sensible method
}

\author{
Franciele Roberta Cordeiro', Margrid Beuter ${ }^{2}$, Camila \\ Castro Roso", Maria Henriqueta Luce Kruse ${ }^{1}$ \\ ${ }^{1}$ Rio Grande do Sul Federal University \\ ${ }^{2}$ Santa Maria Federal University
}

\begin{abstract}
Aim: to describe the possibilities of nursing care for the terminally ill oncology patient from the perspective of the nursing team. Method: This is a descriptive, exploratory study, using a qualitative approach. To gather the data, we used the creative and sensible method, through a group dynamic called Almanac. The data obtained was later analyzed based on French discourse analysis theory. Results: The discourses of the nursing professionals point to a preoccupation with pain management and the comfort of the terminally ill oncology patient, proposing the adoption of pharmaceutical therapy, as well as recreational activities and multidisciplinary actions to minimize the pain. Discussion: Based on the nurses' perspectives of pain management, solidarity and sensibility are demonstrated to be motivational elements for professionals, in order to find strategies that enable some quality in the dying process. Conclusion: We are able to foresee the possibility of providing a dignified death for people diagnosed with a neoplastic illness who do not have any chance of survival, even though sometimes the nurses are faced with limitations in how to approach the ideal holistic healthcare.
\end{abstract}

Keywords: Pain; Death; Oncologic Nursing; Palliative Care 


\section{INTRODUCTION}

Of all chronic diseases, cancer appears to have some particular importance regarding national and health organization policies, both in Brazil and across the world. The disease is characterized by progressive development, over a short period of time and, in many cases, it results in severe functional degradation; it makes no differentiation between gender, age or social class ${ }^{(1)}$.

The preoccupation with this disease has increased since the second half of the $20^{\text {th }}$ Century, when the world panorama of infectious-contagious diseases was removed from the spotlight with the use of antibiotics, and the prevalence of an elevated number of patients with neoplasties became an influence on the development and discoveries of chemotherapies and radiotherapies ${ }^{(2)}$.

The incidence of cancer has risen in Brazil and the rest of the world, in addition to which, the population is aging as a result of an increase in life expectancy. This environment is a result of the economic and social changes that have happened in the world in recent decades, as urbanization and industrialization processes have grown due to the expansion of capitalism, resulting in meaningful changes in population lifestyles ${ }^{(3)}$. These changes can be observed in new dietary habits, which have moved away from dishes made from natural products, to fast foods filled with preservatives; exposure to external risk factors, such as solar radiation and the inhalation of chemical products resulting from new urban developments. Along with other factors, these elevate the risk of developing degenerative chronic diseases, such as cancer $^{(4)}$.

In 2008, the International Research of Cancer Agency, under the World Health Organization (IRCA/WHO), estimated that there were twelve million new cases of the illness in the world, especially in developing countries. Among these neoplasties, the majority attacked: the lungs (1.52 million), breast (1.29 million) and colon and rectum (1.15 million). Based on mortality rates, we observe that lung cancer is quite aggressive (1.31 million deaths), followed by stomach cancer (780,000 deaths) and liver cancer $(699,000 \text { deaths })^{(4)}$. In Brazil, it is estimated that skin cancer, of a non-melanoma type 
is the most common among the population $(114,000)$, followed by prostate tumors $(52,000)$, women's breast cancer $(49,000)$, colorectal cancer $(28,000)$, lung cancer $(28,000)$, stomach cancer $(21,000)$ and utero-cervical cancer $(18,000)^{(3)}$.

Data shows that the survival of patients is directly linked to the stage of the illness and the lifestyle of the patients. The survival of patients with cancer is defined as the relationship between the incidence and mortality rates; it is estimated as $50 \%$ over five years for all types of tumor ${ }^{(3)}$. From the point of view of both cure and survival, pain management is an important challenge for nurses, because of the difficulties of managing the suffering through pharmaceutical and complementary measures. Among these, we highlight the use of opioids and their derivatives that can generate some uncertainty: for the patients, who fear getting intoxicated and becoming addicted to the drugs, and for the professionals, regarding the best dose that can show sedative or analgesic effects, while avoiding undesirable side effects ${ }^{(5)}$.

Pain is a prevailing symptom in patients with cancer. Complaints from these patients, relating to the development of the illness, are not only linked to the physical aspects and the extent of the spread of the tumor, but they also involve a degree of individual subjectivity. Around $70 \%$ of oncology patients mention some type of pain during the neoplastic disease, which points to the importance of evaluating and managing analgesia, especially the use of opioid-based drugs ${ }^{(5)}$.

Pain is the result of an interaction between the physical and chemical aspects in response to a certain harmful stimulus. After being "decoded", the stimulus, in association with the humor, cultural and emotional aspects of the individual, results in the perception of pain (6). Pain is characterized according to intensity and duration. Acute pain is an immediate response to a certain reflex or exposure to a harmful agent, for example, burn or trauma pain. Chronic pain "represents a phenomenon of nociceptive sensitivity, with a reduction of the pain threshold (allodynia), amplification of the response to harmful stimulus (hyperalgesia), and the sensation of prolonged pain after stimulus" ${ }^{\prime \prime: 3)}$.

In a survey using the database of Latin-American and Caribbean Literature in Health Sciences (LILACS, in Portuguese), it is possible to observe some studies about pain, 
mostly in the area of pediatric oncology. In this research, there is clear evidence of the care that the nursing team provides to these patients and the interest of the accompanying relatives who are supporting the child with neoplastic illness. From this survey, it was possible to identify some of the nursing practices that aim to control the pain. We draw attention to the development of techniques that permit a higher absorption and efficiency of the proposed therapy, for example, hypodermoclysis (subcutaneous infusion as an alternative method for hydration and the administration of drugs), which contributes significantly to the control, not only of the pain, but also of other common symptoms in the terminal phase, such as nausea and vomiting. The clinical competencies and practical abilities required in these cases, demand, from the nurse, a constant process of updating, in order for them to facilitate a dignified end to life. However, there are few studies that describe the nursing care regarding pain management and comfort of the hospitalized oncology patient, and especially few that integrate the bio-psychosocial aspects and their repercussions to build knowledge and care in the nursing field.

Based on this scenario, we pose the question: How does the nursing team develop nursing care for the oncology patient who is far from any chance of cure? To answer this question, this study intends to describe the possibilities of nursing care for terminally ill oncology patients, from the point of view of the nursing team.

\section{METHOD}

This is a descriptive and exploratory study, using a qualitative approach. This type of approach enables a research design that is better suited to the subject under investigation and to the needs and concerns of the researcher, ensuring the flexibility of the study and thus permitting a holistic understanding of the questions raised in different scenarios $^{(8)}$. To produce the data used in this study, we used the Creative and Sensible Method (MCS, in Portuguese). MCS minimizes the bias generated by the overlapping of the many different human feelings. Hence, "the absorption of sensible impressions is the 
way we learn the properties of a phenomenon or object so it can be scrutinized through a critical analysis and the appreciative judgment, which are both tasks of the critic-sensible investigator" ${ }^{\prime \prime}(9: 1)$.

The subjects of this study were three nurses and two nursing technicians who have worked in oncology for more than two years. The study's location was in the oncology units of a public hospital in the south of Brazil: to be more specific, the study was carried out at the chemotherapy and radiotherapy walk-in clinics, the children and adolescents' cancer treatment center and the bone marrow transplant center. The data was gathered in February 2011, in the auditorium of a community center for children with cancer, linked to the teaching hospital which was the study's location.

As a technique for data production, we used the Creativity and Sensibility Group Dynamic (DCS, in Portuguese) named "Almanac", which took around 70 minutes. The DCS "Almanac" assists in the production of data by participants pasting images and drawings onto an A4-sized sheet after listening to the debate question. The participants were requested to write their names on the back of the sheet to identify their own production, as well as to enable them to be associated with their transcribed discourses for later analysis. The group dynamic "Almanac" was divided into five steps, as described by MCS: $\mathbf{1}^{\text {st }}$ Step: the professionals of the nursing team were welcomed by the researcher and the research support team. The support team contributed with the organization of the group dynamics. Later, a relaxation technique was performed; $\mathbf{2}^{\text {nd }}$ Step: the participants were invited to sit on chairs placed around a round table, where the materials for the group dynamic were placed. The aim of the study and the steps of the group dynamic were explained. Following this, the guiding debate question was asked ("What is the nursing care for an oncology patient without any chance of cure, in the place where you work?"), which was written on a board in the room so that all the participants could read it throughout the group dynamic; $3^{\text {rd }}$ Step: a time limit was set (between 15 and 20 minutes) for production of the almanacs. Each participant started their individual production; $\mathbf{4}^{\text {th }}$ Step: the participants presented their almanacs and a discussion ensued, then the guiding debate question was debated; $\mathbf{5}^{\text {th }}$ Step: time was made available so 
that the members of the group could voice their opinions, to collectively validate the topics under discussion. After agreement by all participants, the group dynamic was ended.

The data produced was transcribed and submitted to French discourse analysis, which tries to identify what is said beyond the superficiality of the discourse, putting it into the context of where the speaker lives, validating the historical and social aspects ${ }^{(10)}$. As a theoretical device for facilitating the analysis, an analytic board was used to assist in looking for meanings in the discourses, through the identification of paraphrases, polysemic processes and metaphoric effects that determine the formation of the discursive process to be analyzed. The board was designed using the existential situations of the nurses and nursing technicians, from which the main theme, the subthemes, the thematic recodification and the analytic comment of the interpretational process could be drawn.

This study followed the ethical standards of Resolution 196/96 of the Brazilian National Health Council, which regulates studies with human beings ${ }^{(11)}$. The study was approved by the Ethics in Research committee in our institution, under the Certificate of Presentation to Ethical Appreciation (CAAE, in Portuguese) registry number 0334.0.243.000-10. Data collection started after approval was given by the competent agencies. The group dynamic was recorded in audio and also photographed, with the authorization of the participants who had all read and signed the Free and Clear Consent Agreement. The participants were identified with the letters "E" (for the nurses) and "TE" (for the nursing technicians), followed by a number in ascending order, according to the exposition of their artistic productions, in order to preserve their anonymity.

\section{RESULTS}

During the group dynamic, many elements relating to the care of patients without a chance of cure were debated. In this section, we present the analysis of the discourses 
uttered by the participants regarding pain and comfort, as these were mentioned during the discussion as concerns during the process of care giving.

Throughout the group dynamic, the participants reported possible alternatives to minimizing the pain, especially the main therapeutic measures which involve the use of medication and the support of respiratory distress:

(...) I believe that it is to find, to make it available everything we have inside the hospital to make that child, that teenager in a terminal stage, without any chance of cure, to feel as much comfortable as possible. Let them have medication, and if they need comfort, they should have $\mathrm{O}_{2}$ (oxygen). (E1)

(...) first, I thought this image with medication, a syringe with a needle, and I used it to illustrate, actually, that people look in a unit when they are hospitalized (...). I cannot agree with a child, a teenager being hospitalized and feeling pain, right? (E1)

As E1 said, that she does not accept the idea of a hospitalized child to feel any pain, this is really something; the child should not feel any pain. Now, we don't have to think that we must save this child, to provide the cure that is not in our hands because we are not God, right? We provide a drug support, to provide support using the machines. (E2)

(...) We worry about pain (...). We look for any kind of provision we can find. Many times, the patient has to do an exam, or anything else, we go together, with the patient, because you know that to leave the patient alone is hard for him, and sometimes he won't make it. Or sometimes we need a pain specialist and sometimes it takes three months to arrive one, so we end up interfering; so we worry a lot about the relief of the pain of the patient, to alleviate his pain. (TE1)

From these discourses, we observe the preoccupation with pain relief for terminally ill patients, either within the context of hospitalization or in the walk-in clinics. The use of pharmaceutical therapy to alleviate pain symptoms was the main step taken by the professionals. The participants also noted the anguish generated by the symptoms of imminent death, especially respiratory discomfort. They presented the use of oxygen as a relief measure to the terminally ill patients. Inter-departmental relationships inside the institution are another aspect mentioned in the discourses, particularly the services provided by the pain clinic to both patients and professionals. Even given the limitations and difficulties of accessing this service, the professionals reported that there was a dialogue with this clinic in order to speed up treatment to meet the demands of the 
patients. Despite this, there were some difficulties encountered in the relationship between the professionals carrying out the therapeutic measures, especially with the doctors, who tended to limit nursing interventions.

I think it is very difficult for nurses dealing with terminal patients, that, as we are the ones that spend (...) 24 hours beside the patients and we get to know their necessities, the frequency and intensity of the pain, if the patient was able to sleep or not, if he is nauseated, the frequency or not of that nausea, and then, the other professionals, especially the doctor, who is the one we interact most often, right? Then he only comes in that moment to prescribe the drugs. (E3)

This is the patient that vomited, went home without a prescribed antiemetic, and is feeling pain and you see him using paracetamol as a terminal patient, and I think that we, from the nursing, we have this dilemma, because we have to find out the medication, we have to call the doctor (...). Because we have a patient complaining about the pain he is having, and no one comes to solve that problem, and we have to solve all issues. And another thing, that I don't know if it is something we didn't learn in the classroom, either technicians, auxiliaries or nurses, we think we are the judges at those moments, you know? John Doe is in pain or not, addicted to morphine. (E2)

Even with the predominance of pharmaceutical measures to handle the pain, some of the professionals mentioned complementary strategies in their caretaking, either by the use of recreational activities or by the sense of welcome and solidarity shared with the patients:

Or bringing some happiness, a game, (...) which are not completely away from nursing, but there is a lot of nursing professionals that use a clown nose, wear some funny clothes, bring some lollypops, some gifts, some toys. (E3)

I put an image of a mother embracing the daughter, because many times we are as mothers to our patients, and they see us, they need a hug, they listen to us, as they need a word you may say that can comfort them, and that helps a lot. And to learn like that, to also listen to them, and sometimes just because they are talking, as they put it out, it alleviates that suffering or even sometimes with the whole pathological problem they have, such as familiar misfits, and we end up, as much as possible, trying to help them in one way or another. (TE1)

The participants mentioned that this moment in the patients' lives could be made less painful by using games and recreational activities or by giving a simple hug, listening to the patients and being open to dialogue. In their discourses, the preoccupation of the 
professionals with the comfort of their patients emerged, through activities including hygiene care, nutrition and follow-up regarding urinary and intestinal movements of the patients:

And as they are patients without any chance of cure, when they arrive at the radio (therapy) section, many of them are already very debilitated, thin, feeling a lot of pain, in a certain situation that they face physical and emotional difficulties, and we end up taking responsibility for all that, the moment we say "Calm down, mom! Everything will be alright!" (E2)

(...) We are worried with the weight of the patients and their nutrition. So I am always checking if they ate, reinforcing the importance of drinking liquids, eating food. (TE1)

One patient arrives on a wheelchair, and you go, trying to move him to a bed, to give him some comfort (...), I don't think I have any conditions to do that in the ambulatory (of chemotherapy). And it is in this sense that I say, like, that I think that when the patient is there (in the chemotherapy ambulatory), if it is palliative measure, if it is to alleviate the pain of the patient, so it is a right of the patient and we are there to do our best. (TE2)

We stress that, in these discourses, the participation of the nursing professionals is represented with respect and awareness of the physical difficulties and emotional and social limitations they face.

\section{DISCUSSION}

In the discourses of the nursing professionals, we observed their preoccupation with the pain of the terminally ill oncology patients and the prevalence of pharmaceutical therapies as a comfort measure to aid these patients. Sometimes, the nurses felt insecure when dealing with the pain and other symptoms of imminent death, resulting in anxiety and doubts regarding the steps to be taken during care-giving. Studies ${ }^{(5,13)}$ have confirmed the necessity of evaluating and interfering in oncologic pain, pointing to the gaps found in the registry, evaluation, systematization and intervention of pain based on specific parameters, because it is seen that, in many cases, the nursing team uses therapeutic and evaluative measures in an empiric and unsystematic format. Many times, such a reality is generated by the unavailability of instruments to evaluate pain, or the 
lack of trained nursing staff to use them, associated with prejudice regarding the nonstop use of medications with double effects, such as opioids. Thus, we observed that each nursing team adopts different approaches to intervention, decomposing the healthcare procedures and making it difficult to evaluate the measures implemented. In this study, the participants stated that they intervened in pain control but they did not specify how they evaluated, systematized and registered this symptom. They also reported situations where the nursing team underestimated the pain of the patients, relating the patient's solicitation of medication as a symptom of their addiction to the drugs used, such as morphine, which, in the end, complicates and limits the analgesic management.

Another study ${ }^{(14)}$ corroborates the fact that nursing teams frequently have difficulties in evaluating and managing the pain of oncology patients, facing the same difficulties mentioned by the nurses and nursing technicians in this research. "This unpreparedness is attributed to the inadequacy of the formation, which leads to a non-evaluation of the pain in a systematic way; an underestimate of the frequency of the occurrences of pain and to ignore the devastating impact of the pain to the individual" ${ }^{\prime 14: 88)}$. This difficulty in approaching and managing the pain of oncology patients is not limited to the nursing team but can be extended to all health professionals. Among the difficulties faced, nurses mention: a lack of information from the doctors, the myths and misconceptions of the sick patients and their relatives, the policies of the health system and inadequate legislation ${ }^{(15)}$.

The positive effects of opioids and other analgesics are well recognized during the treatment and sedation of terminally ill patients, however, it is also relevant and pertinent to consider the application of non-pharmaceutical measures as part of the therapy to control pain. Recreation can be used as a caring instrument with these patients, either in the form of a play, a game, conversation, the use of music therapy and other techniques that can be used to promote relaxation for both the patient and the accompanying relative ${ }^{(16)}$. 
However, it is important to recognize the individuality and gain the acceptance of the patient regarding the proposed activities, always respecting the patient's will. If he prefers silence and distance, we must provide an environment that would be as welcoming to him as the recreational environment to others.

Allied with the palliatives of pain relief, other forms of comfort can be considered as acts that fortify and console patients, in a way so as to promote wellbeing and pleasure. The act of comforting reflects well both on those who are being taken care of and on those providing the care, allowing the growth and development of both agents ${ }^{(17)}$.

In agreement with the literature, the nursing team studied aims to meet all the needs of the patient using the resources available, establishing a relationship of confidence and safety with the people involved in caring. Thus, to provide comfort, it is necessary to transform the environment into a warm, caring, loving place, which promulgates relief, security and wellbeing, including the presence of professionals who provide security and empathy ${ }^{(12)}$.

Dying in a dignified way is a right for everyone. In a time of volatile relationships, the liquidity of feelings and the ephemerality of values, we observe, walking in hospital aisles, ever more empty and lonely wards. Loneliness, as it is understood here, is not only the physical lack of people, but also the distancing of human beings within relationships. In the moment of death, patients are usually with their relatives, who generally keep some distance because of the insecurity and anxiety that death provokes. In addition to this, matters regarding the degradation of the body, such as the appearance of lesions, the onset of vomiting and loss of control of the sphincters generates some repulsion and distance on the part of both relatives and professionals, who do not know how to deal with these aspects. In the case of oncology patients, the majority of external tumors have an unpleasant appearance and odor, which makes the patient feel ashamed and he tries, on his own account, to be as distant as possible ${ }^{(18)}$. The nursing team must be sensitive to their patients' needs as many times they go unnoticed, and this interferes not only with the physical symptoms of the disease, but 
also provokes a disruption of the nurse-patient relationship, due to the reduction of the patient's self-esteem and his shame regarding the illness.

Many times in oncology, the care required to provide comfort to meet the patient needs, goes beyond the physical pain of the patient, demanding perspicacity and sensibility from the nursing staff. Cancer carries a social stigma, directly associated to mortality. For people who have no possibility of cure, their feelings of pain and anguish are intensified, as compared to those of the general spectrum of clinical patients, as well by their having an awareness of the proximity of death and the feelings that this phase of life awakens. Therefore, comfort and pain are intrinsically connected. Based on this, it is evident that there is a necessity to adopt strategies that are guided by the philosophy of "palliative care", as this model brings together care-giving based on therapeutic measures of comfort, that aim to provide a more dignified and tranquil death. The concept of palliative care-giving is being vastly implemented in the area of health, especially by nurses and by medical staff. The philosophy of care-giving based on the principles of bioethics, provided to patients with illnesses that are far from any possibility of cure and to their relatives, intends mainly to respect the notion of non-maleficence, in order to guarantee the dignity of the terminally ill patient ${ }^{(19)}$. There have been many discussions regarding the palliative care given nowadays; however, we observe that, despite this, the majority of hospitals do not adopt this philosophy, either in a specific hospitalization unit for these patients or through consulting with specialists. Besides the increased demand, we observe a lack of resources in this area, from hospitals to home care, in prejudice to investment in therapies that use high-cost technologies to promote a cure, which receive more financial support from the institutions.

\section{CONCLUSION}

The discourse of the nursing professionals demonstrates a lack of preparedness to work with pain management during the dying process. Such a fact can be attributed to the 
infrequent use of instruments to evaluate pain and other symptoms, which lead to the non-identification of those symptoms in the patients.

We have identified the necessity for policies that allow dignity in the process of dying, as well as the availability of resources to alleviate pain and the utilization of recreational strategies in hospital care-giving, which, to date, is filled with daily norms and routines that block the development of actions of higher amplitude regarding the bio-psychosocial aspects of caring for the terminally ill.

On the other hand, the participants in this study demonstrated that nursing professionals use mainly pharmaceutical measures to alleviate both the pain and the discomforts of an imminent death. There is some discrete use of recreation in care-giving, developed by both nursing professionals and professionals in other areas. The listening, the welcoming and the demonstrations of care given by the nursing team are valuable roles highlighted by this study, as these are elements considered essential to qualify as care-giving in oncology nursing, besides being decisive in the relationship between nursing professionals and the patient. We must stress the importance of the application of the philosophy of palliative care, which will improve the quality of life of the patients and their relatives dealing with diseases that have no possibility of cure.

\section{REFERENCES}

1. Hart CFM, Landskron LMF, Ferreira R, Picheti JS, Duarte VM, Bermudez CS et al. Câncer: uma abordagem psicológica. Porto Alegre: Age; 2008.

2. Instituto Nacional do Câncer [Brasil]. Ações de enfermagem para o controle do câncer: uma proposta de integração ensino-serviço. 3a ed. Rio de Janeiro: INCA; 2008.

3. Instituto Nacional do Câncer [Brasil]. A situação do Câncer no Brasil. Rio de Janeiro: INCA; 2010.

4. World Health Organization [homepage on the Internet]. Cancer incidence in five Continents. Cited 2010 Sept 3. Available from: http://www-dep.iarc.fr/.

5. Waterkemper R, Reibnitz KS, Monticelli $M$. Dialogando com enfermeiras sobre a avaliação da dor oncológica do paciente sob cuidados paliativos. Rev Bras Enferm. 2010 mar ;63(2):334-9.

6. Silva LMH, Zago MMF. O cuidado do paciente oncológico com dor crônica na ótica do enfermeiro. Rev Latino-Am Enferm. 2001 jul; 9(4):44-9.

7. Prado WA. Neurofisiologia e neuroquímica da dor aguda e crônica. In: Andrade Filho ACC. Dor: diagnóstico e tratamento. São Paulo: Roca; 2001. p.1-5.

8. Polit DF, Bek CT, Hungler BP. Fundamento de pesquisa em enfermagem: métodos, 
utilização e avaliação. Porto Alegre: Artmed; 2006.

9. Cabral IE. A contribuição da critica sensível á produção do conhecimento em enfermagem. In Anais do $11^{\circ}$ Seminário Nacional de Pesquisa em Enfermagem. 2001 maio 27-30; Belém [PA], : Aben [PA]: 1995.

10. Orlandi EP. Análise de discurso: princípios e procedimentos. $8^{a}$ ed. Campinas (SP): Pontes; 2009.

11. Ministério da Saúde [BR]. Resolução no 196, de 10 de outubro de 1996. Diretrizes e normas regulamentadoras de pesquisa envolvendo seres humanos.Diario Oficial da União 16 out 1996; seção 1 .

12. Rosa LM, Mercês NNA, Santos VEP, Radünz V. As faces do conforto: visão de enfermeiras e pacientes com câncer. Rev Enferm UERJ. 2008 jul; 16(3):410-4.

13. Venegas ME, Suazo SV. Análisis de la Teoría de los Síntomas Desagradables en el Cuidado de la Enfermería Paliativa Oncológica. Revista Cubana de Enfermería. 2011; 27(2):141-150.

14. Recco DC, Luiz CB, Pinto MH. O cuidado prestado ao portador de doença oncológica: na visão de um grupo de enfermeiras de um hospital de grande porte do interior do estado de São Paulo. Arq Ciênc Saúde. 2005 abr; 12(2):85-90.

15. International Society of Nurses in Cancer Care (ISNCC). Diretriz técnica da dor por câncer. Rev Nursing. 2001; 41(4):7-8.

16. Beuter M, Alvim NAT. Expressões lúdicas no cuidado hospitalar sob a ótica de enfermeiras. Esc Anna Nery Rev Enferm. 2010; 14(3):567-74.

17. Waldow V. O cuidar humano: reflexões sobre o processo de enfermagem versus processo de cuidar. Rev enferm UERJ. 2001; 9(3):284-93.

18. Elias N. A solidão dos moribundos, seguido de, Envelhecer e morrer. Rio de Janeiro: Zahar; 2001.

19. Sousa A, França J, Nóbrega M, Fernandes M, Costa S. Palliative care: a conceptual analysis. Online Braz J Nurs [Internet]. 2010 [cited 2012 May 4]; 9(2). Available from: $\quad$ http://www.objnursing.uff.br/index.php/nursing/article/view/j.1676-

4285.2010.2947/667.

Received: $12 / 07 / 2012$

Approved: 08/03/2013

Cordeiro FR, Beuter M, Roso CC, Kruse MHL. Pain and the dying process: nurses' perspectives using the creative and sensible method. Online braz j nurs [Internet]. 2013 Apr [cited year mouth day]; 12 (1): 106-19. Available from: 119 http://www.objnursing.uff.br/index.php/nursing/article/view/3989 